\title{
Erratum to "Frontal Lobe Dysfunction in a Depressed Patient Who Survived a Suicide Attempt by Jumping from the Bridge on the Han River"
}

\section{Kiwon Kim ${ }^{1}$ and Hong Jin Jeon ${ }^{1,2} \otimes$}

${ }^{1}$ Department of Psychiatry, Depression Center, Samsung Medical Center, Sungkyunkwan University School of Medicine, Seoul, Republic of Korea ${ }^{2}$ Department of Health Sciences \& Technology, Department of Medical Device Management \& Research, and Department of Clinical Research Design \& Evaluation, Samsung Advanced Institute for Health Sciences \& Technology (SAIHST), Sungkyunkwan University, Seoul, Republic of Korea

Psychiatry Investig 2017;14(6):904-908

https://doi.org/10.4306/pi.2017.14.6.904

In the original publication, the total number of suicide attempts in 2015 in Figure 1 is incorrect. The error has been fixed in the paper.

Figure 1. The number of suicide attempts by jumping from bridges of the Han river each year (2003-2015).

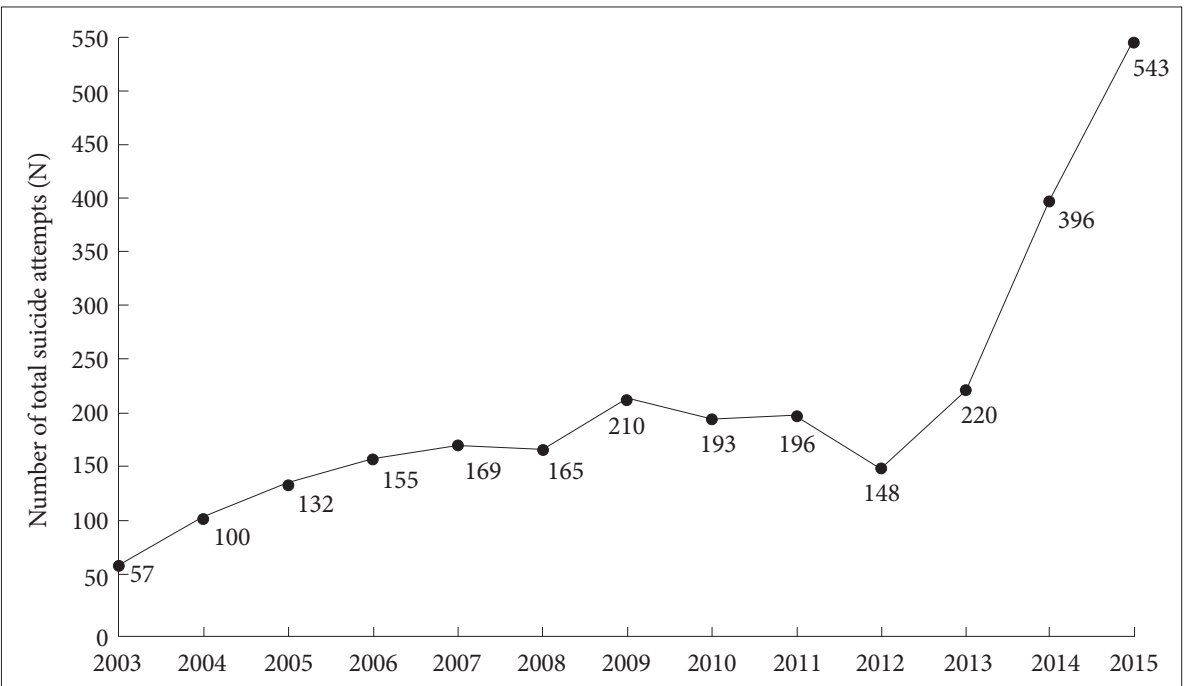

(c) This is an Open Access article distributed under the terms of the Creative Commons Attribution Non-Commercial License (http://creativecommons.org/licenses/bync/4.0) which permits unrestricted non-commercial use, distribution, and reproduction in any medium, provided the original work is properly cited. 